\title{
DOCUMENTAÇÃO JURÍDICA: INTERFACES DA LEITURA DOCUMENTÁRIA, LINGUAGEM E ANÁLISE DE DISCURSO NO TRATAMENTO DA INFORMAÇÃO
}

LEGAL DOCUMENTATION: INTERFACES OF READING, LANGUAGE AND DISCOURSE ANALYSIS IN THE TREATMENT OF INFORMATION

DOCUMENTACIÓN JURÍDICA: INTERFACES DE LECTURA DOCUMENTAL, LENGUAJE Y ANÁLISIS DEL DISCURSO EN EL TRATAMIENTO DE LA INFORMACIÓN

Roseli Miranda ${ }^{1}$

Cibele Araújo Camargo Marques dos Santos ${ }^{1}$

${ }^{1}$ Universidade de São Paulo

Correspondência

${ }^{1}$ Roseli Miranda (D)

Universidade de São Paulo

São Paulo, SP

E-mail: rmiranda.cedoc@gmail.com

JITA: IC. Index languages, processes and schemes.

Submetido em: $24 / 05 / 2018$

Aceito em: 16/05/2018

Publicado em: 27/08/2018 
RESUMO: Reflexões sobre o tratamento da informação na Documentação Jurídica, com base na tríade: leitura documentária, linguagem jurídica e análise de discurso. Nesse contexto, discutem-se terminologia e representação da informação, em função do hermetismo da linguagem e da dificuldade para o profissional bibliotecário na identificação os tipos de discursos jurídicos presentes nos documentos da área. Conclui ressaltando a importância da pesquisa sobre a análise de discurso voltada para os tipos de discursos empregados na Documentação Jurídica, que podem propiciar o reconhecimento da estrutura do documento e das partes que contém informações relevantes, contribuindo com a representação da informação.

PALAVRAS-CHAVE: Documentação jurídica. Análise documental. Linguística. Terminologia.

ABSTRACT: Reflections on the treatment of information in the Legal Documentation, based on the triad: documentary reading, legal language and discourse analysis. In this context, terminology and information representation are discussed, due to the hermetism of language and the difficulty for the professional librarian in identifying the types of legal discourses present in the area documents. It concludes by emphasizing the importance of the research on discourse analysis focused on the types of discourses used in the Legal Documentation, which can promote the recognition of the structure and the parts of the document that contain relevant information, contributing to the representation of information.

KEYWORDS: Legal information systems. Documentary analysis. Linguistics. Terminology.

RESUMEN: Reflexiones sobre el tratamiento de la información en la Documentación Jurídica, con base en la tríada: lectura documental, lenguaje jurídico y análisis de discurso. En este contexto, se discuten terminología y representación de la información, en función del hermetismo del lenguaje y de la dificultad para el profesional bibliotecario en la identificación de los tipos de discursos jurídicos presentes en los documentos del área. Concluye resaltando la importancia de la investigación sobre el análisis de discurso orientado a los tipos de discursos empleados en la Documentación Jurídica, que pueden propiciar el reconocimiento de la estructura del documento y de las partes que contiene informaciones relevantes, contribuyendo con la representación de la información.

PALABRAS CLAVE: Sistema de información jurídica. Análisis documental. Linguística. Terminología. 


\section{INTRODUÇÃO}

A Documentação Jurídica, como instrumento de exercício social pressupõe acesso e disponibilidade devendo, por estes motivos, ter aprimoradas suas formas de organização e representação da informação. A área se distingue por conter tipologias documentais com características singulares, as quais advêm das fontes formais do Direito. Por tratar-se de um campo de especialidade, conhecê-las, torna-se uma condição necessária para lidar com a terminologia e linguagem jurídica, comumente apontada pelo profissional bibliotecário, como aspectos relevantes para o tratamento técnico desta informação.

Segundo Passos (1994), a informação jurídica difere de outros tipos de informação em um aspecto importante, a longevidade. Ela destaca que de forma distinta de outros campos de especialidade, o texto jurídico é perene para fins de consulta, na utilização como referência e na aplicação e uso em situações ocorridas em diferentes períodos e por vários tipos de entidades do campo jurídico. Consequentemente, há uma tendência de acumulação nos repositórios de informação e de documentação da área, tornando premente e imperativa a necessidade de ter a organização e representação da informação fortemente ancorada em premissas teóricas e metodológicas, a fim de garantir a recuperação.

A linguagem jurídica tem reputação de codificada no contexto do vocabulário linguístico. A exemplo de outras ciências, o Direito possui terminologia própria que desenvolve conceitos e termos com definições muito particulares. Além disso, o discurso jurídico, muitas vezes, traz implícitas, informações que são propositadamente apresentadas de maneira indireta e obscura, tornando a leitura técnica e o trabalho de representação da informação ainda mais desafiador para o bibliotecário.

Nessa perspectiva, considera-se que a interface da leitura documentária, da linguagem jurídica e da análise de discurso pode lançar algumas luzes na questão e auxiliar o bibliotecário no trabalho de representação da informação. Desse modo, com base na abordagem de autores que pesquisam essas temáticas é que se apresenta o presente estudo.

\section{A LEITURA DOCUMENTÁRIA NA ÁREA JURÍDICA}

Independente do segmento de atuação profissional, o trabalho do bibliotecário relaciona-se com a leitura, seja essa compreendida como ato social, como práticas educativas ou ainda como fruto de atividades técnicas do fazer cotidiano. Existe um vínculo intrínseco entre o bibliotecário e a leitura e qualquer menção a este profissional, imediatamente remete ao ato de ler e ao ambiente da biblioteca.

A leitura realizada pelo bibliotecário como parte das atribuições do trabalho técnico consiste em uma atividade vital que interfere diretamente nas formas de organizar e representar o conhecimento. A esse respeito, Chartier (1999) analisa que o temor da perda

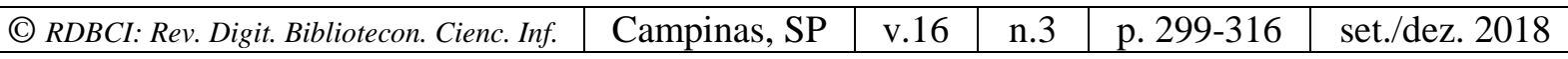


trata de uma inquietação da cultura escrita, assim como a preservação do patrimônio frente à proliferação textual, os quais trazem a inquietude do excesso, exigindo o uso de instrumentos capazes de triar, classificar e organizar. Partindo desta reflexão, avalia-se que o bibliotecário não pode se posicionar como um leitor comum, devido a sua responsabilidade técnica e social na execução do trabalho de representação e mediação da informação. Os estudos desenvolvidos no âmbito da leitura documentária sinalizam tratar de atividade de cunho profissional que não pode ser realizada baseada em elementos pragmáticos e não sistematizados.

Apesar da relevante importância, no mapeamento da produção brasileira sobre informação jurídica, realizado por Edilenice Passos, que abrange trabalhos publicados de 1948 até 2017 (ano em que ocorreu a última atualização) são poucos os registros de estudos que discutam a leitura dos documentos jurídicos ou mesmo de leitura documentária, cujos estudos começam a ser publicados no Brasil a partir da década de 1980. Dentre o período analisado pela pesquisadora, uma das raras publicações refere-se a pesquisa de Silva (2010) que aborda conceitos e técnicas de leitura voltadas para o profissional que atua com informação jurídica, com ênfase na indexação. Ainda em consulta a literatura de Ciência da Informação, verifica-se que a leitura realizada pelo bibliotecário em áreas de segmento especializado propicia uma visão pouco objetiva dos requisitos que qualificam uma leitura como técnica.

Conforme esclarece Moura (2004), a leitura técnica incide numa abordagem plena dos itens informacionais, com a finalidade de recolher dados que poderão possibilitar a representação desses itens no sistema de informação. Nesse contexto, esse procedimento técnico incorpora dois outros processos, ou seja, a análise do assunto e a indexação, os quais tornam possível a identificação e extração dos termos conceituais que representam o conteúdo do documento, reconhecidos como necessários na representação da informação através de uma linguagem de indexação. De modo simplificado, a leitura técnica, visa, através do uso de ferramentas apropriadas, reconstituir a informação veiculada no texto original para representação.

$\mathrm{Na}$ área jurídica, verifica-se que a tônica dada para a leitura do bibliotecário pode conter influência de objetivos pontuais, visto que o trabalho dos operadores do Direito em geral é precedido pelo uso de informações que são determinadas pelas características do segmento jurídico em questão. Logo, é comum o uso constante de informações de fontes especializadas que são consideradas como insumo propulsor.

Miranda (2017) entende que para lidar com essa comunidade é necessário o estudo das fontes de informação jurídicas, pois considera que estas exercem papel relevante no desempenho das atividades que compete ao profissional de Direito. $\mathrm{O}$ aumento escalonado da produção jurídica e a rapidez na circulação das informações tem intensificado a necessidade do operador do Direito contar com suporte informacional especializado.

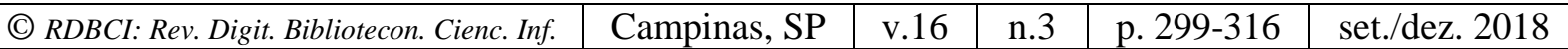


Por essa razão, a leitura do bibliotecário pode ter papel decisivo e valor significativo, sobretudo na realização de atividades que envolvem o trabalho de organização e de representação da informação, podendo demandar maior atenção e exigir estudos mais detalhados em função da temática da área. Cabe explicar que este trata de um campo em que a comunidade necessita de informações precisas, de fontes seguras e confiáveis, pois equívocos ou erros na representação da informação podem inviabilizar a realização de operações jurídicas, gerar perdas em disputas judiciais e até ocasionar prejuízo financeiro. Outro ponto é que sem o conhecimento da linguagem jurídica e de sua documentação, o bibliotecário se perceberá limitado tanto na ação de leitura como na execução do trabalho de representação documentária.

Em virtude das características da área é importante que o bibliotecário invista no estudo formal da leitura, com vistas a adquirir maior proficiência nesta atividade como também para diminuir as barreiras nas demais etapas do tratamento documentário. Fujita (2004) explica que o processo de leitura pode demonstrar simplicidade, mas possui implícita uma complexidade que decorre da forma como a informação é processada, dos objetivos da leitura, do próprio leitor e do contexto.

A leitura documentária faz parte do conjunto de procedimentos compreendidos no contexto da Análise Documentária, disciplina que se caracteriza especialmente por abordar problemas operatórios, metodológicos e teóricos voltados para a representação de conteúdos documentais (KOBASHI, 1992). Desta forma,

o conceito de leitura documentária surge como proposta de aperfeiçoamento da Análise Documentária, sendo uma modalidade específica no processo global de leitura a partir da qual é dado o início da própria operação de Análise Documentária. (LARA 2011, p. 100)

Em síntese, a leitura documentária visa condensar e representar o conteúdo documental com a dupla finalidade de facilitar a recuperação da informação e satisfazer as necessidades da comunidade usuária, promovendo sua circulação e uso. Do processamento da leitura é gerada a informação documentária que tem por função realizar a identificação dos itens informacionais do documento, de modo que propicie condições do usuário decidir se necessita ou não consulta-lo. Kobashi (1994) observa que, enquanto operações documentárias, essas atividades são realizadas no âmbito de instituições informacionais e por isso devem refletir o contexto organizacional. Para fins de aplicação, isso significa que o tratamento e recuperação da informação devem ser sistematizados e se firmar numa política global que represente os parâmetros institucionais.

Entre os pesquisadores que contribuíram para o desenvolvimento do tema, Cintra (1987) foi pioneira em abordar o uso de estratégias de leitura considerando o estudo da tipologia textual e os esquemas formais de organização do texto. De acordo com suas reflexões, o bibliotecário que atua em campos especializados pode se apoiar nos modelos \begin{tabular}{l|l|l|l|l|l}
\hline (C) RDBCI: Rev. Digit. Bibliotecon. Cienc. Inf. & Campinas, SP & v.16 & n.3 & p. 299-316 & set./dez. 2018 \\
\hline
\end{tabular} 
padronizados utilizados pela área. Em geral, documentos com tais características tendem a facilitar o trabalho de leitura, pois permitem o reconhecimento das partes que contém informações relevantes como também ampliam a probabilidade de adquirir maior precisão na forma de representação da informação à medida que ocorrer o aprimoramento na área de atuação.

Em referência aos modelos documentais no campo do Direito pode-se utilizar como exemplo, a ata que trata de um documento testemunhal de assentamento. Este é caracterizado por conter informações como data, hora e local com endereço; nome das pessoas presentes, cargo ou qualificação; declaração de abertura da sessão pelo responsável e secretário, e se aplicável o registro da junta comercial onde a entidade esta sediada. Na estrutura textual desse documento, os assuntos discutidos seguem em geral, obediência à ordem ou pauta do dia, subsequentemente são expostas as deliberações tomadas. Em seu protocolo final é registrada a lavratura de encerramento presidido normalmente por um texto padronizado. Basicamente toda ata (independente do modelo societário adotado pela entidade) possui estrutura e informações apresentadas de forma sistematizadas.

Em direção semelhante, Kobashi (1994) apresenta estudo no qual define e sistematiza uma metodologia voltada para a elaboração de informações documentárias, com ênfase na condensação e representação de conteúdos. Tendo por objeto a elaboração de resumos, estabelece um conjunto de procedimentos constituídos com base na noção de estrutura e superestrutura textual. Conforme elucida, o conceito de tipologia textual vincula-se a noção de que todo texto apresenta uma sintaxe que metodiza suas partes componentes. Destarte, essa forma de organização textual se constitui em um elemento vital para compreensão do significado do texto, pois permite que o leitor monitore a leitura e assimile dentre as várias informações o que é central. Lara (1994) corrobora com essa posição e recomenda que o bibliotecário procure se apoiar nas formas de organização textual e em quadros de referência que possibilitem o reconhecimento do vocabulário da respectiva área.

No campo do Direito o reconhecimento da fonte produtora pode facilitar a leitura documentária. A documentação jurídica possui três fontes principais, que compreende a doutrina, a legislação e a jurisprudência sendo que o bibliotecário pode e deve utilizá-las como apoio para execução do seu trabalho. Um aspecto da área é o uso de modelos padronizados em que a estrutura textual do documento segue padrão e ritos procedimentais comuns, condição que exige que o leitor bibliotecário reconheça quais partes de determinado tipo de documento possui as informações relevantes.

Aspectos linguísticos, psicológicos e sociológicos estão entre os elementos que também interferem no processo da leitura e apreensão do texto. Fujita, Nardi e Santos (1998) defendem a interação do leitor-texto, por meio do uso de estratégias ou esquemas, enquanto conjuntos de conhecimentos que englobam desde o vocabulário, estrutura textual, conhecimento do assunto e até da vivência particular de mundo do indivíduo. Em sua

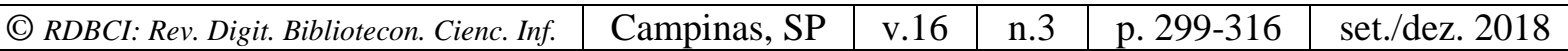


abordagem analisam a leitura documentária sob a ótica da norma ISO 5963 (norma de documentação sobre método de análise de documentos, determinação dos assuntos e seleção de termos para a indexação) e identificam aproximações com as propostas de leitura de Giasson (composta pela tríade leitor-texto-contexto) e de Brown (baseadas em ações conscientes do leitor), ambas apoiadas no processo cognitivo.

A memória é também apontada como recurso para realizar inferências na interpretação textual, se associado a situações relacionadas ao cotidiano das atividades técnicas, podem surgir como quadro de referência estocado através de conhecimentos prévios, o qual pode ser acionado no momento da leitura. Moura (2004) afirma que a apropriação terminológica pelo leitor-bibliotecário é assinalada por um armazenamento contínuo dos descritores aplicáveis a área de atuação, constituindo uma enciclopédia particular. Como leitor profissional esta é uma condição essencial para o bibliotecário que atua em campos de especialidades. Em sua avaliação, o bibliotecário pode com o transcorrer do tempo, desenvolver ao longo de suas atividades profissionais, determinadas habilidades, tornando-se capaz de incorporar novas informações, conforme a familiaridade com a terminologia. Cintra (1987) concorda com esta opinião e pondera que à medida que a área de especialidade evolua, é provável que haja um aprimoramento correspondente. No Direito há uma tendência para que entidades jurídicas operem em determinados segmentos de atuação, condição que pode favorecer a assimilação da terminologia. Contudo, essa característica também exige que os bibliotecários ingressantes na área, estudem e busquem alternativas de aprendizado e aprimoramento devido às características comuns do usuário da área.

Para Silva (2010), os aspectos existentes no processamento da leitura são ainda pouco conhecidos por alguns profissionais da área jurídica, o que justifica a continuidade de produção de literatura sobre o assunto, reforçando os benefícios que a leitura documentária pode promover para a organização e representação da informação neste contexto, contribuindo para a qualidade do tratamento documentário, e promovendo maior eficiência no acesso à informação.

\section{A LINGUAGEM JURÍDICA E SUA TERMINOLOGIA}

Segundo Reale (2001), cada ciência manifesta-se em uma linguagem e para conseguir alcançar a visão unitária do Direito é preciso adquirir um vocabulário. Como outras disciplinas do conhecimento humano, o Direito é representado em terminologia própria e como linguagem de especialidade, possui definições, conceitos e termos aplicáveis de acordo com as distinções de cada uma de suas ramificações. Por isso, desde os anos iniciais de sua formação, o jurista é estimulado a se dedicar aos estudos da terminologia jurídica a fim de poder comunicar-se adequadamente.

A linguagem jurídica é compreendida como elemento fundante para os operadores do Direito, meio pelo qual devem se expressar e ser exercida a ciência jurídica. A forma de

\begin{tabular}{|c|c|c|c|c|c|}
\hline (C) RDBCI: Rev. Digit. Bibliotecon. Cienc. Inf. & Campinas, SP & v.16 & n.3 & p. 299-316 & set./dez. 2018 \\
\hline
\end{tabular}


comunicação dos operadores dessa área espelha o modo de atuação do profissional. Considerando que é da natureza da linguagem comunicar-se (JOSEPH, 2002) pode-se afirmar que faz parte dos objetos de estudos desta área, a linguagem legislativa, a linguagem judiciária, forense, notarial, tributária, dentre outras que podem representar especificidades dos segmentos de atuação.

Bittar (2001) explica que o jurista normalmente pesquisa para estabelecer qual será o tipo de linguagem através da qual manifestará os conhecimentos sobre determinado objeto de estudo. Com a análise da linguagem não só provê elementos para a comunicação do pensamento como também fornece uma pluralidade imensa de outras formas de simbologia, que numa abordagem semiótica da linguagem cientifica, possibilita pontuar conceitos, expectativas, intenções, ideias e significações, elementos os quais, são presentes nos textos jurídicos.

Em seu cotidiano o operador do Direito, seja na a comunicação verbal ou escrita, utiliza uma linguagem de especialidade que é considerada por muitos codificada, rebuscada, prolixa e formal a tal ponto que é entendida por alguns como elitizada e até causa de segregação do conhecimento jurídico e do acesso à justiça.

Em menor grau de exigência, o bibliotecário como profissional mediador da informação também é demandado com relação a essa linguagem. Atuar na área jurídica exige que este seja célere, objetivo e possua domínio e perícia técnica, habilidades que podem ser comprometidas se não houver conhecimentos mínimos sobre a linguagem e terminologia. Diferente do que pode ocorrer em outros campos de atuação, a ação do trabalho do bibliotecário produz efeitos imediatos e impactos diretos na atividade jurídica, sendo esta, uma condição que gera cobranças e grande exigência em relação à competência na execução do trabalho a ser realizado. Qualquer erro operacional pode implicar em sérias consequências já que informações e documentos são visto como insumos de trabalho.

Por isso, é vital que o bibliotecário compreenda plenamente a significação atribuída aos termos e conceitos empregados na área. Barreto (1994) observa que a informação só possui poder de ação quando adquire a condição de mensagem, com intenção específica e assimilação possível. A incompreensão ou equívoco, sobre o significado de um determinado termo, poder gerar incapacidade e erros de resultados em atividades como a pesquisa bibliográfica, organização e representação da informação. $\mathrm{O}$ trabalho do bibliotecário jurídico envolve questões vinculadas à linguagem e é de sua responsabilidade fazer a mediação entre a linguagem especializada, a linguagem natural e a linguagem documentária utilizada para representar informações e documentos. Nesse sentido, a Linguística Documentária e a Terminologia, podem oferecer parâmetros para nortear o tratamento técnico informacional.

No âmbito da Ciência da Informação desenvolveu-se como subcampo a Linguística Documentária, que analisa com minúcia o processo linguístico relacionado ao tratamento da

V.16

n.3

p. $299-316$

set./dez. 2018


informação. Esse campo de estudo surgiu na década de 90 na Espanha a partir dos trabalhos de García Gutierrez que se baseou na Linguística Estruturalista, na Análise de Discurso, na Semiótica, na Terminologia e na Lógica Formal.

A Linguística Documentária tem como finalidade subsidiar os processos de representação para organização e recuperação de informações. García Gutierrez (1990) assinala que o objetivo fundamental da disciplina é elaborar modelos úteis para a Análise Documentária e para Linguagem Documentária. Como esclarece, o objeto da Linguística Documentária é a estrutura da Documentação para organização de conteúdos codificáveis e decodificáveis, sendo dividida em duas partes principais: a estrutura da produção da informação (considera a organização e apresentação das ideias do autor); e a estrutura de representação (considera o discurso do produtor). É pertinente lembrar que nesse campo, o trabalho é realizado em essência com informações textuais, a fim de propiciar a circulação, recuperação e uso para o público de interesse. De modo que,

Cabe à Linguística Documentária compor os quadros de referência para análise, avaliação e construção da linguagem documentária, entendida como linguagem de informação, associando os níveis sintáticos-semânticos-pragmáticos para identificar com clareza a inserção do signo documentário no plano sistêmico e no plano funcional, objetivando-o no tempo, no espaço e na cultura. (LARA E TÁLAMO, 2006, p. 206)

A Linguística Documentária propõe critérios metodológicos para tratar a produção documentária e sua representação apoiada em referências sócias cognitivas e de linguagem das comunidades a que se destinam os produtos informacionais. Reconhecendo a natureza da comunicação documentária trabalha no campo operacional em atividades concernentes a seleção de vocabulários, em políticas de indexação (por meio de propostas de indicadores de conteúdo) e na construção de linguagens documentárias, tendo como referência as terminologias da área.

Tálamo (2001) considera que a garantia de funcionamento comunicativo da linguagem documentária vincula-se profundamente ao uso da Terminologia como elemento operativo, pois a interpretação do significado de um termo a ser representado pode demandar sua recontextualização por meio de determinada terminologia de especialidade. Isto é, a terminologia realiza o controle de significação das palavras e intermedia a transferência de informação junto à comunidade provendo a comunicação.

A terminologia no sentido simples da palavra designa o conjunto de termos técnicos de uma determinada área e as ideias que estes representam. Em sentido amplo, refere-se ao uso e estudo de termos, isto é, especifica as palavras (simples e compostas) que são em geral utilizadas em contextos específicos. Em suma, pode-se dizer que o objeto de estudo da Terminologia são os conjuntos de termos de um domínio e os conceitos por ele designados (BARROS, 2004, p. 34). 
Ao analisar as tendências da terminologia no campo do Direito, Silva (2010) aborda dois aspectos importantes: a propensão para certo hermetismo devido ao uso de palavras de difícil compreensão ou propositadamente de sentido obscuro e a incorporação de palavras da linguagem natural ao vocabulário jurídico que neste campo adquire outra conotação e sentido. Com efeito, estes aspectos se relacionam com a dificuldade de compreensão de conteúdos documentais, pois provoca dúvidas sobre os conceitos da área.

Reale (2001) observa que no mundo jurídico não é incomum expressões correntes e de uso popular adquirirem um sentido técnico especial. Para ilustrar cita como exemplo a palavra "competência" que na linguagem natural pode ser compreendida como "capacitado", "eficiente" ou "preparado", mas na linguagem jurídica significa que tem poder para determinar e resolver, porque "competência" juridicamente refere-se à medida ou extensão da jurisdição.

A Terminologia permite identificar os meios de expressão dos conceitos (se é próprio de um domínio, se é emprestado ou é utilizado por vários domínios), determinar suas características, como também entender as relações que um conceito mantém com os demais, dentro de um determinado campo do saber. Através desta, é possível identificar, de forma sistemática, o vocabulário de uma determinada especialidade e analisá-lo (VOGEL, 2007). Para isso, emprega-se como metodologia, uma série de operações encadeadas que incluem a coleta ou compilação, a análise, o processamento, a descrição dos termos, o neologismo (constituição de novos termos) e a normalização (CABRÉ, 1999).

Compreendendo que sem a documentação o trabalho terminológico não pode ser realizado, Cabré (1999) sustenta que o processo de sistematização só pode se realizar através da análise dos discursos especializados, materializados nas comunicações entre os especialistas, principalmente através dos textos. A Terminologia também pode ser empregada como recurso para instrumentalizar a construção de linguagens documentárias e/ou para representar informações. Contudo, a linguagem documentária tem objetivos distintos (LARA, 2004). Isso indica que apesar da Terminologia ser um elemento decisivo na construção de linguagens documentárias (sobretudo em campos de especialidade), de forma isolada, não garante o êxito da comunicação documentária.

Diante disso, considera-se que a Linguística Documentária e a Terminologia enquanto campos disciplinares podem balizar o trabalho do bibliotecário jurídico, visto que de forma combinada permitem substituir as práticas empíricas pelo uso de metodologias que instrumentalizam o tratamento e representação da informação, promovendo sua padronização e, portanto sua institucionalização.

\section{O DISCURSO E A REPRESENTAÇÃO DA DOCUMENTAÇÃO JURÍDICA}

A organização e representação da Documentação Jurídica têm como base referencial

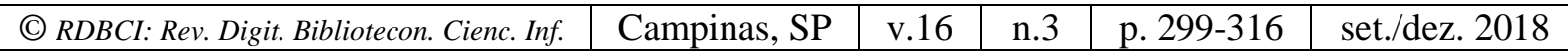


os pressupostos da Documentação enquanto campo disciplinar. O objeto desta é o documento que é composto de mensagem e linguagem.

Como vimos os problemas relacionados à representação da informação no campo do Direito são derivados da leitura dos documentos jurídicos e também do hermetismo da linguagem dessa comunidade. Os textos jurídicos são a base referencial para o trabalho dos operadores do Direito e nestes há manifestações discursivas que afetam a forma de organização e de representação da informação.

Em seu livro, “O que falar quer dizer”, o sociólogo francês Pierre Bourdieu (1998, p. 29) observa que não há palavras inocentes, e se deslocarmos essa ênfase para a Ciência do Direito, as palavras podem assumir mais de uma configuração e sentido. É fato reconhecido que a linguagem jurídica normalmente é veiculadora de ideologia já que os elementos linguísticos de que se constitui manifestam-se impregnados de significação ideológica. Os operadores do Direito com frequência utilizam a linguagem para se posicionar discursivamente e se impor aos sujeitos. Por isso, para se decodificar essa linguagem é preciso compreendê-la também como veiculadora de ideologia, amalgamada de significados e de sentidos próprios, que são muitas vezes apresentados de forma aparentemente neutra. Essa característica faz parte dos artifícios que geram dificuldades no trabalho de representação da informação de documentos jurídicos. Não é raro ou incomum que textos jurídicos contenham intenções veladas.

No tratamento documentário um problema recorrente é o tempo limitado para se realizar a leitura de livros e documentos a serem classificados e indexados. O trabalho do advogado tem como base o uso da informação e pode suscitar pressão nas tarefas a serem realizadas pelo bibliotecário, já que é alta a demanda por informações, documentos e pesquisas, além do fator econômico que também é preponderante.

Na tentativa de resolver os problemas de significação no tratamento da documentação jurídica, alguns profissionais recorrem à análise de conteúdo, buscando extrair sentidos dos textos, visando obter melhores resultados. Porém este tipo de análise, pode se apresentar de forma insuficiente. Sobre o uso deste método, Kobashi (1994) alerta que o registro de dados é um dos principais problemas devido à falta de rigor na definição das categorias utilizadas para descrever os dados. Outro problema comum é a falta de uniformidade dos dados coletados nos textos. No que concerne à área do Direito, o emprego desta metodologia pode demandar maior tempo e atenção do que se é possível dispensar. É preciso considerar ainda que existem diferentes modalidades de discurso jurídico, as quais são exclusivas e aplicadas em tipos documentais determinados. Além disso, o vocabulário não é constituído somente de termos de pertinência jurídica, compreendendo também o uso de termos ordinários do vocabulário comum, fato que pode abrir precedente para ambiguidades, em função da polissemia. 
Com base nos estudos do discurso e do texto surge como recurso a análise de discurso, que pode auxiliar na identificação de informações relevantes que não são apresentadas de forma direta ou suficientemente claras em alguns textos jurídicos. A priori é conveniente esclarecer que a análise do discurso é uma prática da linguística, surgida na década de 1960 como uma tendência de estudos da linguagem, que consiste em analisar a estrutura do texto e a partir disto, entender as construções ideológicas presentes.

Em Pêcheux (1988), seu maior articulador, sentido e sujeito são constituídos num processo simultâneo. A noção de sujeito é definida pela posição e pelo lugar de onde se fala, isto é, do interior de uma concepção discursiva que é regulada por uma formação ideológica. Orlandi explica que o objeto da análise do discurso é o próprio discurso. Por conseguinte, seu interesse principal é o de estudar a "língua funcionando para a produção de sentidos" (1999, p.17), condição que permite analisar o texto. Nessa conjuntura, tem por finalidade compreender como um objeto simbólico produz sentidos, e como ele está investido de significância para os sujeitos. Portanto, implica em identificar como o texto organiza os gestos de interpretação que relacionam sujeito e sentido. A análise do discurso não se restringe apenas a interpretação textual, pelo contrário, opera considerando seus limites e os seus processos de significação. De modo distinto da análise de conteúdo, não busca uma explicação verdadeira, mas procura identificar os significados presentes no texto de forma que permita escutar as demais significações presentes para compreender como eles se constituem.

Dada às particularidades da Documentação Jurídica, considera-se que de forma complementar a leitura documentária realizada pelo bibliotecário, a análise do discurso pode trazer contribuições que podem auxiliar na identificação das formações discursivas características dos textos desse campo do saber. Porém, convém esclarecer que não se tem como objetivo realizar um trabalho interpretativo sistemático do texto como é realizado pelo jurista em busca do sentido e da interpretação jurídica. Pelo contrário, busca-se identificar os elementos característicos comuns dos tipos textuais da área e seus respectivos assuntos, os quais são muitas vezes apresentados de forma indireta, em função das próprias características textuais.

Logo, torna-se necessário clarificar que na análise do discurso não há formulas mecanizadas para realizar a análise do texto ou métodos que proponha a identificação das informações principais, sendo que cada documento exige que o analista, de acordo com os objetivos que persegue, mobilize os conceitos e dispositivos teóricos de interpretação para realizar a análise. Por outro lado, os dispositivos teóricos podem mediar o trabalho de descrição e interpretação, sustentando-se nos princípios gerais da análise do discurso.

Partindo desse entendimento, ao analisar um texto, o analista precisa ter em mente que os dizeres não se limitam a palavras a serem decodificadas. Em geral, são produzidos em determinadas condições que de alguma forma, deixam pistas presentes no texto, os quais o

V.16

n.3

p. $299-316$

set./dez. 2018


analista pode apreender. Dentre esses elementos, as condições de produção (contexto imediato e amplo) podem revelar pistas importantes. O contexto imediato pode ser compreendido como as circunstancias de enunciação ou as próprias condições de produção do texto no sentido estrito. Já o contexto amplo deriva do quadro social, histórico e ideológico, a forma como está posicionado numa determinada instituição e na sociedade. Os processos de produção do discurso contemplam três fases, sua constituição (partindo da memória), sua formulação (condições de produção) e sua circulação, que ocorre em determinadas circunstâncias e certas condições (ORLANDI, 1999).

Semelhante aos outros campos do saber, o discurso jurídico sempre representa uma tomada de posição do sujeito falante, e de igual modo, reflete na composição textual do documento, as condições de produção deste. Isto é, via de regra, o texto explícita o motivo que fundamenta sua constituição, sua instituição de origem, os litigantes (partes envolvidas) etc. Ademais, todo documento jurídico é constituído com um algum propósito que já busca prever as circunstâncias e condições em que deve ocorrer sua circulação. Essa condição oculta ou apresenta de forma subjetiva a ideologia, pois o indivíduo é interpelado em sujeito por esta, para que se produza o dizer. Pêcheux (1988) entende que é característica comum da ideologia dissimular sua existência no interior de seu próprio funcionamento. Artifício que frequentemente causa impressão que um dado sentido interpretado no texto, parece evidente.

Um discurso se organiza de determinada forma porque o sujeito se inscreve em uma formação discursiva para representar um sentido particular e não outro. Aliás, a formação discursiva se define como aquilo que numa determinada formação ideológica, delimita o que pode e deve ser dito (ORLANDI, 2007). Presume-se que todo discurso contido em textos de documentos jurídicos tem um objetivo pontual para apreender determinado alcance. Essa questão evidencia-se ao analisar que o operador do Direito é capacitado profissionalmente não só para exercer a interpretação do discurso jurídico, mas também para elaborá-lo.

A prática jurídica se manifesta por meio dos textos, os quais refletem pensamentos e posicionamentos. O discurso jurídico se faz presente em todas as instâncias de suas fontes de informação. Em cada espécie de texto, há um modelo de discurso jurídico que possui suas regras de construção particulares. Assim, cada fonte de informação jurídica possui propriedades que estão presentes na estrutura textual. Considerando os pressupostos da Análise do Discurso verifica-se que é possível identificar as características particulares presentes no discurso textual proveniente dessas mesmas fontes. $\mathrm{O}$ reconhecimento destas pode tornar a tarefa de leitura, análise e representação dos documentos jurídicos menos complexos. Bittar (2003) aponta quatro grupamentos principais reconhecidos nos discursos jurídicos, os quais podem ser encontrados com maior recorrência nos textos da área, são estes: o normativo, o burocrático, o decisório e o científico. Em cada uma dessas modalidades destacam-se funções jurídico-discursivas basilares.

No discurso normativo, segundo o autor citado acima, predomina a função que 
corresponde à tarefa de conduzir comportamentos (permitindo ou obrigando), eleger valores, dirigir a interpretação e os afazeres dos agentes públicos. O discurso normativo é o mesmo do legislador, indivíduo investido de competência para dar cumprimento à regulamentação de condutas. $\mathrm{O}$ legislador exerce o papel discursivo dirigindo-se à comunidade que recebe os textos por ele criados. Esse tipo de discurso é normalmente veiculado em textos de linguagem normativa, como em códigos de normas jurídicas, leis, decretos, portarias, instruções normativas que em geral são de competência do poder legislativo no âmbito das esferas federal, estadual e municipal.

Por sua vez, no discurso burocrático vigora a função ordinatória, que corresponde às atividades de regularização, acompanhamento e condução de procedimentos, com vistas a nortear o curso dos ritos institucionais. $\mathrm{O}$ discurso burocrático é subordinado ao discurso normativo. Em sua configuração é comum o uso da forma imperativa, com expressões do tipo "Junte-se aos autos os documentos", ou "Cumpram-se", "Dê-se andamento ao despacho", etc. Bittar (2001) ressalta que a informação jurídico-procedimental é difundida por meio desse tipo de discurso em certidões, atestações, retificações, descrições, dentre outros.

Outra modalidade é o discurso decisório que corresponde à atividade aplicativa, dirimidora (esclarecendo ou anulando) e conclusiva, sendo responsável por materializar os parâmetros normativos. Este modelo de discurso ilustra a prática jurídica que pode cunhar, alterar ou extinguir direitos com base nos embates textuais, documentos, argumentos, provas, etc., podendo ser lavrado por um juiz ou autoridade administrativa competente. As sentenças judiciais são apresentadas como exemplo dessa modalidade por Bittar (2001). Conforme o autor esclarece, a sentença é o ato no qual se resolve o processo em instância judicial. E como ato de linguagem precisa ser escrito para assumir sua forma concreta, devendo ser emitido por um órgão investido de autoridade para julgar, o qual deve apresentar o relatório, o fundamento e dispositivo, visto que estas são as suas três partes formais elementares, também deve obedecer aos ritos processuais e estar inserido no contexto de um processo na esfera jurisdicional.

A quarta modalidade é denominada discurso científico. Este modelo exerce-se, por sua função cognitivo-interpretativa, que corresponde às atividades de conhecimento, informação, distinção, classificação, interpretação, explicação, sistematização e críticas decorridas dos outros três modelos de discurso. O discurso científico é instituído da vontade de produzir sentido jurídico e é basicamente voltado para interpretação, crítica e compreensão dos demais discursos. O discurso jurídico científico é caracterizado por meio de documentos como livros, no qual há ensinamentos teóricos conceituais, lições doutrinárias, críticas, resenhas, etc.

Ao analisar cada modalidade de discurso, verifica-se que estes carregam características que podem ser associadas às tipologias documentais provenientes das fontes de informação do Direito. Passos $(1994 ; 2009)$ lembra que a Legislação é assinalada por ser de produção exclusiva do poder estatal (segundo a esfera de competência), sendo apresentada em duas

n.3

p. $299-316$
set./dez. 2018 
formas básicas, a informação legislativa que resulta do processo legislativo (representada em emendas, pareceres, relatórios, etc.) e a informação jurídica normativa, que se ocupa de regular a vida dos cidadãos. Já a Doutrina distingue-se por sua forma analítica e/ou descritiva, que pode ser expressa pela emissão de opinião particular sobre algum assunto. E finalmente, a jurisprudência caracteriza-se por sua forma interpretativa, atuando na elucidação dos conceitos gerais da norma legislativa.

Ao relacionar os tipos de discursos jurídicos apontados por Bittar, pode-se afirmar que o discurso normativo é presente em documentos oriundos da Legislação, sobretudo os que são compreendidos como informação jurídica normativa. O discurso decisório e burocrático é comumente encontrado em documentos procedentes da jurisprudência. Ressalva-se, porém, que considerando as espécies documentais jurídicas, os discursos decisório e burocrático podem constar configurados também em documentos comprobatórios e de assentamento. Por último, avalia-se que o discurso científico é encontrado nas fontes doutrinárias. Nesse contexto, defende-se que o reconhecimento do tipo de discurso jurídico e de sua respectiva fonte, pode em adição aos outros recursos utilizados pela Análise do Discurso facilitar o trabalho de tratamento documentário.

Finalmente, é necessário observar que a aplicação da Análise do Discurso na área de Documentação Jurídica é constitui-se em uma proposta que deve ser estudada de forma mais aprofundada. No entanto, o estabelecimento de modelos referenciais que possam facilitar a compreensão e o reconhecimento dos tipos jurídicos discursivos, permitirá o alcance de resultados mais efetivos no que tange a representação da informação jurídica.

\section{CONSIDERAÇÕES FINAIS}

O presente artigo procurou debater sobre a importância de três elementos fundamentais para o trabalho do bibliotecário jurídico: a leitura documentária, a linguagem jurídica e a análise do discurso aplicado a esse campo.

Ao analisar a literatura da área, verificou-se que há relevantes estudos voltados para a leitura documentária, porém poucos tratam especificamente a Documentação Jurídica. Avalia-se que enquanto atividade componente do tratamento documentário, esta se mostra relevante por mobilizar recursos que podem auxiliar no aperfeiçoamento da representação da informação, contribuindo para a sistematização das atividades que a compõem. Com importância equivalente, figura a linguagem jurídica, linguagem especializada cujo reconhecimento e domínio permitem não somente o adequado tratamento documentário, mas também a construção de linguagens documentárias e vocabulários controlados para o processo de indexação da informação como vistas à recuperação e acesso eficiente destes documentos. Com efeito, avalia-se que os estudos da Linguística Documentária e da Terminologia oferecem soluções que podem instrumentalizar as atividades de organização e representação, bem como promover a institucionalização das informações. 
O artigo oportuniza refletir sobre a possibilidade da análise do discurso ser compreendida como recurso para tratar documentos jurídicos, observando que no campo do Direito os tipos de discursos são reconhecidos, mas não considerados no tratamento documentário. Através da análise do discurso observou-se que os textos jurídicos estabelecem a significação em um dado espaço material concreto, expondo-se a organização da discursividade. Porém, essa proposta pode ficar restrita a documentos da área jurídica, onde o discurso é um elemento preponderante e cuja análise pode auxiliar na representação. Verificou-se que a terminologia jurídica, embora demande trabalho, não impede $o$ reconhecimento das características dos tipos de discurso jurídico, pelo contrário. As marcas textuais de expressões características podem auxiliar na associação com a tipologia documental jurídica, o que permite analisá-lo, considerando tanto sua estrutura textual como discursiva.

\section{REFERÊNCIAS}

BARROS, Lídia A. Curso básico de terminologia. São Paulo: Edusp, 2004.

BARRETO, Aldo. A. A questão da informação. São Paulo em Perspectiva, v.8, n 4, out./dez. 1994. Disponível em

<http://www.seade.gov.br/produtos/spp/v08n04/v08n04_01.pdf>. Acesso em 15.08.2013

BITTAR, Eduardo Carlos B. Metodologia da pesquisa jurídica: teoria e prática da monografia para os cursos de direito. São Paulo: Saraiva, 2001.

BITTAR, Eduardo Carlos B. Linguagem jurídica. São Paulo: Saraiva, 2003.

BORDIEU, Pierre. O que falar quer dizer. In: A economia das trocas linguísticas. São Paulo: EDUSP, 1998.

CABRÉ, Maria Teresa. La terminología: representación y comunicación. Barcelona: IULA-UPF, 1999.

CHARTIER, Roger. A aventura do livro do leitor ao navegador. São Paulo: UNESP, 1999.

CINTRA, Anna Maria. Estratégias de leitura em documentação. In: Smit, J.W. (Coord.). Análise documentária: análise da síntese. Brasília: IBICT, 2ª ed., p. 29-37, 1987.

FUJITA, Mariângela Spotti Lopes. A Leitura Documentária na perspectiva de suas variáveis: leitor-texto-contexto. DataGramaZero, v. 5, n. 4, ago. 2004

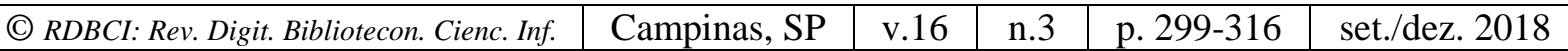


FUJITA, Mariângela Spotti Lopes; NARDI, Maria Izabel Aspeti.; SANTOS, Silvana. A leitura em análise documentária. Transinformação, Campinas, v. 10, n.3, p.13-31, set/dez. 1998.

GARCÍA GUTIÉRREZ, Antonio Luis. Estructura linguística de la documentación: teoria y método. Murcia: Universidad, Secretariado de Publicaciones, 1990.

KOBASHI, Nair Yumiko. A elaboração de informações documentárias: em busca de uma metodologia. Tese (Doutorado em Ciências) - Escola de Comunicação e Arte, Universidade de São Paulo, São Paulo, 1994.

JOSEPH, Miriam. O Trivium: as artes liberais da lógica, gramática e retórica. São Paulo: Realizações, 2002.

LARA, Marilda Lopes Ginez. Linguagem documentária e terminologia. Transinformação, Campinas, n.16 set/dez 2004.

LARA, Marilda Lopes Ginez. Conceitos de Organização e Representação do Conhecimento na ótica das reflexões do Grupo Temma. Revista Informação \& Informação, Londrina, v. 16, n. esp., jan/jun 2011.

MIRANDA, Ana Cláudia Carvalho de; MIRANDA, Erlano Silva de. Fontes de informação jurídica. Encontros Bibli: revista eletrônica de biblioteconomia e ciência da informação, Florianópolis, v. 22, n. 50, p. 76-90, set. 2017.. Disponível em: <https://periodicos.ufsc.br/index.php/eb/article/view/1518-2924.2017v22n50p76>. Acesso em: 15 mai. 2018.

MOURA, Maria Aparecida. Leitor-bibliotecário: interpretação, memória e as contradições da subjetividade. Perspectiva em Ciência da Informação, v. 9, n.2, p.158-169, jul/set. 2004.

ORLANDI, Eni Puccinelli. Análise de Discurso: princípios e procedimentos. $7^{\text {a ed. }}$ Campinas: Pontes, 2007.

ORLANDI, Eni Puccinelli. A linguagem em seu funcionamento: as formas de discurso. São Paulo: Brasiliense, 1983.

PASSOS, Edilenice. O controle da informação jurídica no Brasil: a contribuição do Senado Federal. Revista Ciência da Informação, Brasília v.23 n.3. set/dez. 1994.

PASSO, Edilenice; BARROS, Lucivaldo Vasconcelos. Fontes de informação para pesquisa em direito. Brasilia: Briquet de Lemos, 2009. 
PÊCHEUX, Michel. Semântica e discurso: uma crítica à afirmação do óbvio. Campinas: UNICAMP, 1988.

REALE, Miguel. Lições preliminares do Direito. São Paulo: Saraiva, 25ª ed., 2001.

SILVA, Andreia Gonçalves. Fontes de informação jurídica: conceitos e técnicas de leitura para o profissional da informação. Rio de Janeiro: Interciência, 2010.

TÁLAMO, Maria de Fátima Gonçalves Moreira. Terminologia e documentação. TradTerm: revista do Centro Interdepartamental de Tradução e Terminologia FFLCH/USP, São Paulo, n.7, p.141-151, 2001.

TÁLAMO, Maria de Fátima Gonçalves Moreira, LARA, Marilda Lopes Ginez. O campo da Linguística Documentária. Transinformação, Campinas, v.18, n.3, p.203-211, set./dez. 2006.

VOGEL, Michely Jabala Mamede. A noção de estrutura linguística e de processo de estruturação e sua influência no conceito e na elaboração de linguagem documentária. 124f. Dissertação (Mestrado em Ciência da Informação) - Escola de Comunicação e Artes, Universidade de São Paulo, 2007.
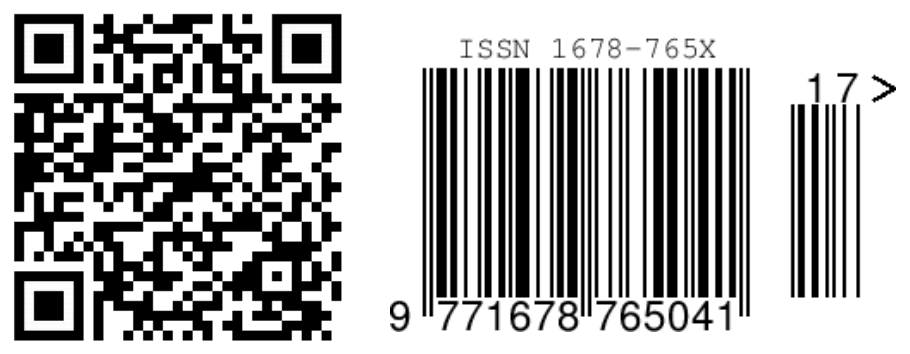